\title{
A Graduação em Arqueologia na UFPel: um currículo na interface entre Arqueologia e Antropologia
}

\author{
Lúcio Menezes Ferreira * \\ Fábio Vergara Cerqueira*
}

\begin{abstract}
FERREIRA, L.M. CERQUEIRA, F.V. A Graduação em Arqueologia na UFPel: um currículo na interface entre Arqueologia e Antropologia. Revista do Museu de Arqueologia e Etnologia, São Paulo, 19: 79-86, 2009.
\end{abstract}

Resumo: Este artigo tem como objetivo apresentar o currículo do novo curso de Bacharelado em Arqueologia da Universidade Federal de Pelotas, criado em 2008, focado na relação com a Antropologia. A primeira parte do artigo trata do contexto histórico da relação teórica e conceitual entre a Antropologia e a Arqueologia. Finaliza esta abordagem histórica avaliando o impacto da globalização sobre o pensamento e práticas arqueológicos. A segunda parte do artigo trata do currículo, apresentando como os conceitos que permeiam o perfil do curso, bem como o impacto da globalização sobre o saber arqueológico, articulam-se nos quatro eixos estruturantes da formação em arqueologia proposta: eixo teórico, diacrônico, metodológico e patrimonial. O texto é encerrado indicando o compromisso do curso com o conceito de multivocalidade (Trigger) e com o diálogo com outras instituições, visando a aprimorar a formação profissional dos arqueólogos em nosso país.

Palavras-chave: Bacharelado em Arqueologia - Antropologia - Formação Profissional - Multivocalidade.

$\mathrm{N}$ osso objetivo, nesse artigo, é apresen tar o currículo da graduação em Arqueologia da Universidade Federal de Pelotas (UFPel), na qual somos professores. Sublinhemos, de saída, que, como todo texto, o nosso também carrega as marcas discerníveis de seu contexto original de produção. Ele foi escrito, inicialmente, para

$\left({ }^{*}\right)$ Universidade Federal de Pelotas-UFPel. Professores de Arqueologia do Bacharelado em Antropologia e Mestrado em Memória Social e Patrimônio Cultural.

<luciomenezes@uol.com.br>,<fabiovergara@uol.com.br> o Fórum de Ensino de Arqueologia na Graduação, oportunamente organizado, por Márcia Bezerra e Fabíola Andréa Silva, no XV Congresso da Sociedade de Arqueologia Brasileira, realizado, entre 20 e 23 de setembro de 2009, em Belém do Pará. ${ }^{1}$

(1) Além das organizadoras e de um dos autores desse artigo (L.M.F.), participaram das discussões do Fórum de Ensino de Arqueologia na Graduação: Jane Beltrão (UFPA/ UNIAM), Abrahão Sanderson Silva e Andreá Scabello (UFPI), Olívia Carvalho (UFS), Sibeli A. Viana (UCG), Andrés Zarankín (UFMG) e Beatriz Thiessen (FURG). 
Sem dúvida, nesse momento em que surgem, no Brasil, diversos novos cursos de graduação em Arqueologia, é importante que reflitamos sobre o perfil dos arqueólogos que formaremos no país. O Fórum de Ensino de Arqueologia na Graduação, ao lado de dois outros artigos (Bezerra 2008; Schaan 2009: 282-287), foram os primeiros gestos a sinalizar essa preocupação. Esse artigo exprime mais um gesto, lançando ao debate nosso currículo. Nossa intenção é discutir para partilhar experiências; debater publicamente para ouvir os colegas e aprimorar, assim, o nosso currículo. O que está em jogo, afinal, é a formação de parte dos futuros arqueólogos brasileiros, os quais, a julgar pelo cenário contemporâneo, defrontar-se-ão com as crescentes demandas públicas, políticas e sociais da Arqueologia.

\section{Coordenadas históricas}

A graduação em Arqueologia da UFPel integra, na verdade, duas habilitações articuladas. Uma em Antropologia Social e Cultural, outra em Arqueologia. Para dizê-lo numa palavra, o currículo da graduação em Arqueologia da UFPel palmilha as coordenadas das relações que a disciplina entabulou, historicamente, com a Antropologia. Antes, porém, de observarmos mais detidamente nosso currículo, vejamos, inicialmente, alguns contornos mais recentes da longa História de relações entre Arqueologia e Antropologia.

Em 1944, enquanto os disparos e bombardeios da Segunda Guerra ainda ecoavam pelo mundo, V. Gordon Childe pronunciou, na Royal Anthropological Institute of Great Britain and Ireland, uma palestra sobre o futuro da Arqueologia (Childe 1944). Segundo ele, o trabalho vindouro da disciplina seria refinar os critérios de classificação tridimensional dos artefatos e promover escavações mais amplas. Duas metas ligavam-se a essa tarefa ulterior: a primeira, estribar bases empiricamente confiáveis para a formulação de sequências cronológicas sobre a distribuição e difusão das "culturas arqueológicas"; a segunda, enfeixar os nós epistemológicos da Arqueologia não apenas com a História, mas, especialmente, com a Antropologia. Uma fortalecida aliança com a Antropologia permitiria o cotejo entre as "culturas arqueológicas" e as culturas nativas ainda vivas; consequentemente, permitiria o estabelecimento de generalizações científicas sobre a natureza e a direção da evolução cultural das sociedades.

Posteriormente, em artigo publicado em 1946, intitulado Archaeology and Anthropology, Childe emite, transparente como cristal, a razão política do nó epistemológico anunciado dois anos antes: a Arqueologia, aliando-se à Antropologia, favoreceria os trabalhos da colonização inglesa no ultramar. Debatendo com os funcionalistas, principalmente com Malinowski e Radcliffe-Brown, Childe argumenta que não bastaria, para os colonizadores, compreender como funcionam as instituições sociais, pois, para saber como funcionam, é preciso, antes, conhecer como elas tornaram-se aquilo que são. Por outra, é necessário conhecê-las em meio às correntes e contra-correntes dos processos históricos, porquanto as instituições são condicionadas pelos eventos do passado. A Antropologia e a Arqueologia, assim, deveriam irmanar-se. Do contrário, ignorar-se-iam os efeitos que as mudanças impulsionadas pelo colonialismo desencadearam e desencadeariam no funcionamento das sociedades nativas. Uma vez estreitadas, a Antropologia e a Arqueologia avaliariam em que medida a administração colonial das mudanças seriam ou não antievolutivas (Childe 1946).

Pelo menos parcialmente, essa pedagogia do colonialismo desmontou-se e misturou-se aos escombros do pós-guerra. Como diz Christian Delacampagne, depois de 1945, o colonialismo e seu esteio, o "racismo científico", foram frontalmente questionados. Três forças históricas correlatas atuaram nesse processo: os movimentos nacionalistas dos povos colonizados; a organização da ONU; e a redefinição epistemológica das Ciências Humanas, iniciada a partir dos anos 1930, com a Teoria Crítica de Frankfurt, e rematada, nos anos 1950, com as "releituras" do marxismo e a voga do estruturalismo (Delacampagne 2000: 256). Sem dúvida, como diria Michel Foucault, depois de 1950, tornamo-nos mais conscientes 
das relações entre poder e ciência (Foucault 1994: 145).

Os anos 1960, no que toca às relações entre Arqueologia e Antropologia, assistiram ao surgimento, nos Estados Unidos, da New Archaeology. Já em artigo publicado em 1955, Philip Phillips anunciara o Leitmotiv da New Archaeology: "Archaeology is Anthropology or it is nothing” (Phillips 1955: 248). Esse enunciado não era propriamente novidade nos Estados Unidos. Franz Boas, em 1902, sublinhou a necessidade de articular a Antropologia à Arqueologia para rastrear os "particularismos históricos das áreas culturais”, cujos marcadores definiam-se pela cultura material (Boas 1902: 3). Em 1958, Phillips e Gordon Willey acresceram ao debate o argumento anunciado em 1955. Opondo-se a Boas, enfatizaram que a Arqueologia, como ciência antropológica, deve dedicar-se às generalizações e comparações interculturais para entender os processos de evolução cultural (Willey e Phillips 1958). Esse argumento foi retomado, em 1962, por Lewis Binford, em célebre artigo, marco da New Archaeology, intitulado Archaeology as Anthropology (Binford 1962). Binford reiterou que o objetivo fundamental da Arqueologia é entender as leis e regularidades do comportamento humano, combinando a abordagem evolucionista de Leslie White e o estudo sistemático do registro arqueológico.

Os autores que maturaram a New Archaeology, ao longo dos anos 1960 e 1970, iteraram parte das proposições de Gordon Childe: a Arqueologia, como ciência inscrita nos quadros da Antropologia, visa a explicar os processos de evolução cultural. Contudo, ao contrário de Childe, não atrelaram diretamente a Arqueologia ao bom e eficiente governo colonial. Mas, conquanto tenham, como sumarizou Matthew Johnson, primado pela objetividade e estatuto científico da Arqueologia, a New Archaeology não foi infensa à política (Johnson 2000). Como assinala Thomas Patterson, com sua busca pelas regularidades e leis evolutivas do comportamento humano, a New Archaeology ratificou os propósitos de estabilidade social (Patterson 1995). Michael Shanks e Christopher Tilley, por sua vez, pontuaram algo que Colin
Renfrew reconhecera já em 1980: a New Archaeology, ao pressupor que as sociedades, em qualquer época e lugar, maximizam os resultados e minimizam os custos, embebe-se da visão e dos valores do capitalismo (Renfrew 1980: 289; Shanks e Tilley 1987: 188).

Frisemos, entretanto, que a História das relações entre Arqueologia e Antropologia é extremamente matizada. Como ressaltou Chris Gosden, elas variam conforme os contextos históricos e institucionais onde se plasmaram, bem como estão, para seguir a fórmula de Heráclito, em permanente mudança (Gosden 1999). O caso dos Estados Unidos é paradigmático a esse respeito. Nem todos acataram fielmente o Leitmotiv da New Archaeology. Em 1978, George Gumerman e David Phillips, por exemplo, argumentaram que a Arqueologia não deveria subsumir-se apenas aos modelos antropológicos (Gumerman e Phillips 1978). Vários autores, de outro lado, mostraram que, historicamente, os elos entre Arqueologia e Antropologia, nos Estados Unidos, ampararam políticas coloniais e a desapropriação de terras indigenas (Cf., por ex: Hinsley 1981; McGuirre 1992). Isso não impede, contudo, que arqueólogos, nos Estados Unidos, reconfigurem, fortalecendo-as, as relações entre Arqueologia e Antropologia. É o que fizeram recentemente William Balée e R. Lee Lyman. O primeiro, mostrando a relevância do modelo dos quatro campos antropológicos (Antropologia sociocultural, Arqueologia, Antropologia Física e Linguística) (Balée 2009); o segundo, evidenciando que o arqueólogo não é um antropólogo de segunda classe (Lyman 2007).

\section{Os marcos do currículo}

Ao montarmos o currículo da habilitação em Arqueologia da UFPel, exemplificamo-nos nas coordenadas históricas acima descritas. Coordenadas que desenham, ainda que em traços difusos, um mapa cujas legendas indicam as dimensões políticas das relações entre Arqueologia e Antropologia. Intentamos, como já o fizeram Balée e Lyman, trilhar mais um percurso na História das relações entre Arqueo- 
logia e Antropologia. Desse modo, orientamos nosso currículo, ademais, pelo norte de, pelo menos, outros dois marcos textuais. O primeiro deles é o artigo de Bruce G. Trigger, lançado em 1984 - Alternative Archaeologies: Nationalist, Colonialist, Imperialist (Trigger 1984). Partindo da teoria do sistema mundial moderno de Immanuel Wallerstein, Trigger evidencia que existem imbricações mutuamente constitutivas entre a Arqueologia e os contextos sociais, econômicos e políticos globais.

O segundo marco é uma obra lançada em 1999: The Archaeological Process, de Ian Hodder (1999). O autor estende as discussões de Trigger, mostrando que as interpretações arqueológicas, no mundo contemporâneo, são diretamente afetadas pelo sistema mundial: a chamada "globalização". Efetuaram-se, desde então, dois padrões gerais nas interpretações arqueológicas: de um lado, uma homogeneização das identidades e culturas globais, pois sítios arqueológicos e artefatos são genericamente concebidos como patrimônios universais da humanidade; de outro, a "globalização" fragmenta a cultura "panpatrimonial", com grupos étnicos e subalternos apropriando-se de sítios arqueológicos e artefatos como símbolos de suas identidades locais.

Hodder argumenta que, diante dessa ambivalência das interpretações arqueológicas contemporâneas, os arqueólogos têm a responsabilidade ética e moral de facilitar o engajamento público nos processos de interpretação arqueológica. Nesse passo, deve-se considerar, segundo Hodder, que a Arqueologia e o patrimônio arqueológico servem a públicos diversos e heterogêneos, gerando múltiplas, complementares ou contraditórias interpretações. Hodder conceitua esse fenômeno como multivocalidade - conceito que, diga-se de passagem, esteve no centro dos debates do XV Congresso da SAB. Multivocalidade, conforme Hodder, significa fortalecer os grupos subalternos e marginalizados para que eles teçam suas próprias representações sobre o passado. O objetivo da multivocalidade é, assim, vazar as variadas interpretações arqueológicas que se encontram represadas nas margens das narrativas oficiais sobre o passado.
Nosso currículo, pois, ao inserir-se num espaço regional - a região Meridional do Rio Grande do Sul -, nem por isso deixa de atentar para o fato de que pisamos num mundo global. Ao demarcar nosso currículo na interface entre Arqueologia e Antropologia, atentamos, portanto, para o conceito de multivocalidade ou, falando-se nos termos de Lynn Meskell, para a noção de que o patrimônio arqueológico é alvo de conflitos e pode materializar sitios de memória negativa (Meskell 2002). Pois, realmente, não existe interpretação arqueológica desatrelada da política, como nos revelam os exemplos radicais das lutas pela repatriação de artefatos e todas as discussões, inauguradas nas últimas décadas, sobre Arqueologia comunitária e descolonização das metodologias arqueológicas (Ferreira 2008; Marshall 2002; Tully 2007; Smith 1999; Smith e Wobst 2005).

Essas questões contemporâneas demandam, com efeito, uma enfática relação entre Arqueologia e Antropologia. Elas exigem que, nos processos de interpretação arqueológica, considerem-se as cosmologias das comunidades locais e como elas são afetadas pelos contextos do sistema mundial. É o que demonstram vários artigos de obras recentes. Citemos duas delas: Places in Mind: Public Archaeology as Applied Anthropology, organizada por Paul A. Shackel e Erve. J. Chambers (2004); e Evaluating Multiple Narratives (Habu, Fawcett e Matsunaga 2008), coordenada por jovens arqueólogos canadenses, livro onde, aliás, B. Trigger publicou seu último ensaio e Hodder dissertou, uma vez mais, sobre multivocalidade (Trigger 2008; Hodder 2008).

Assim é que depositamos forte carga antropológica no currículo de graduação em Arqueologia da UFPel. Os(as) alunos(as), durante os três primeiros semestres, cursam diversas disciplinas de teoria antropológica, que versam, para caracterizá-las de maneira abrangente, sobre evolucionismo, funcionalismo, estruturalismo, antropologia contextual e etnologia. Em seguida, a partir do quarto semestre, o curso se divide em quatro linhas interligadas.

A primeira linha é o eixo teórico. Preside-se pela fundamentação epistemológica da Arqueologia. Insere a disciplina no quadro das Ciênci- 
as Sociais e na História do pensamento arqueológico. Visa a capacitar o(a) arqueólogo(a) para superar a abordagem estritamente empírica e tipológica, embasando-o(a) nas teorias e métodos arqueológicos. Eis as disciplinas que compõem essa linha:

- Específicas: Introdução à Arqueologia; Teoria Arqueológica I; Teoria

Arqueológica II;

- Complementares: História do Pensamento Arqueológico; História do

Pensamento Antropológico;

Etnoarqueologia.

A segunda linha é o eixo diacrônico. Conferirá um caráter geral à formação, propiciando o conhecimento dos estudos arqueológicos de diferentes épocas e regiões, pré-históricas e históricas. Promoverá abordagens comparativas e o contato com diferentes alteridades, analisando-se diversos contextos espaço-temporais. Elucidará, por fim, como arqueólogos(as) aplicam teorias arqueológicas e antropológicas em variados contextos, articulando-se em nossa grade curricular, desse modo, as disciplinas das Linhas 1 e 2. Forma-se pelas seguintes disciplinas:

- Específicas: Pré-História Geral I; Pré-

História Brasileira I; Pré-História

Brasileira II; Arqueologia Histórica I;

Arqueologia Histórica II;

- Complementares: Arqueologia do

Oriente Próximo Antigo; Arqueologia

Clássica; Arqueologia Pré-Colombiana;

Pré-História do Rio Grande do Sul.

A terceira linha, por seu turno, é o eixo teórico-metodológico e prático. Capacitará o(a) arqueólogo(a) para as atividades de campo e laboratório (produção, análise e interpretação dos dados), tanto em sentido tecnológico quanto humanístico, dialogando-se com áreas afins e concretizando-se a imbricação entre as Linhas 1,2 e 3 de nossa grade curricular. Esse eixo prevê, ainda, a constituição de habilidades interdisciplinares no campo geobiológico, por meio de disciplinas voltadas ao uso de tecnologias e metodologias de geoprocessamento e de interpretação de dados biológicos, assim como no estabelecimento de interrelações entre dados materiais e etnográficos. As disciplinas que integram esse eixo são:

- Especificas: Prática de Laboratório I; Prática de Laboratório II; Prática de Campo I; Prática de Campo II; Cartografia e Geoprocessamento; Geologia; Zooarqueologia;

- Complementar: Antropologia Física.

Por fim, a quarta linha, denominada como eixo patrimonial. Ata-se, aqui, o nó de todas as linhas de nosso currículo. Atém-se às finalidades políticas e ao engajamento social dos(as) arqueólogos(as), no interior e fora da academia. Dito de outro modo, as discussões de teoria, método e eixo diacrônico convergirão para a dimensão pública do trabalho arqueológico, relacionando-o com as seguintes temáticas: memória social, patrimônio arqueológico, musealização das coleções e sítios arqueológicos, bem como a atuação no campo do licenciamento e arqueologia de contrato. Em suma, é a linha que percorre a dimensão multivocal das interpretações arqueológicas. Tais são suas disciplinas:

- Específicas: Patrimônio Cultural; Arqueologia Pública; Educação Patrimonial; Musealização da Arqueologia e da Antropologia;

- Complementares: Gestão de Acervo

Arqueológico; Arqueologia de Contrato.

\section{Arqueologias multivocais}

Uma última reflexão, para finalizar a apresentação de nosso currículo. Bruce Trigger - um dos arqueólogos que, como vimos, serviu-nos de norte -, em seu último ensaio, aqui já citado, ponderou que o indivíduo, como pertencente a um grupo, não é uma entidade absoluta e fechada em si mesma (Trigger 2008). Está cultural e politicamente ligado a redes diversas, desde a família à comunidade, desde o Estado nacional ao sistema mundial; e, segundo ele, é na senda das trocas multivocais que o indivíduo floresce, pode intercambiar experiências, 
organizar-se e contestar as pretensões hegemônicas do mundo global. Obviamente, como não somos panglossianos, sabemos que um curso de graduação em Arqueologia não poderá contestar as pretensões hegemônicas da "globalização". Nosso curso, contudo, assim como qualquer indivíduo, está ligado e quer ligar-se a redes diversas. Para que ele seja eficaz e possa aperfeiçoar seu currículo, devemos, certamente, contar com a experiência, colaboração e crítica de nossos colegas brasileiros e estrangeiros. Afinal, nosso desejo, ao tentar percorrer mais um caminho na História das relações entre Arqueologia e Antropologia, é o de ajudar a construir Arqueologias multivocais.

\section{Agradecimentos}

Ao CNPq e ao Laboratório de Ensino e Pesquisa em Antropologia e Arqueologia da UFPel (LEPAARQ), pelo apoio.

A todos os participantes do Fórum de Ensino de Arqueologia na Graduação, pelas calorosas discussões, que nos ajudaram a repensar e melhorar esse artigo. A Francisco Silva Noelli e Pedro L.M. Sanches, que leram a versão original desse texto, e que, igualmente, ajudaram-nos a melhorá-lo.

Dedicamos esse artigo a todos os nossos colegas e alunos do Bacharelado em Antropologia da UFPel, partícipes da construção da Arqueologia na UFPel.

FERREIRA, L.M. CERQUEIRA, F.V. The Bachelor of Archaeology of UFPel, Brazil: a program in the interface between Archaeology and Anthropology. Revista do Museu de Arqueologia e Etnologia, São Paulo, 19: 79-86, 2009.

\begin{abstract}
This article aims to present the program of the new Bachelor of Archaeology of the Universidade Federal of Pelotas, Brazil, created in 2008, focusing in the relation between Archaeology and Anthropology. The first part of the article concerns with the historical context of the theoretical and conceptual relation between Anthropology and Archaeology. This approach finalizes with the evaluation of the impact of the globalization over the archaeological thought and praxis. The second part deals with the program of the course, presenting how the concepts that permeate the profile of the course, as well as the impact of the globalization over the archaeological knowledge, articulate themselves in the branch of the four axes that constitute the proposed archaeological building: the theoretical, the diachronic, the methodological and the patrimonial ones. The text ends indicating the compromise of the course with the concept of multivocality (Trigger) and with the dialogue with other institutions, in order to advance in the professional building of the archaeologists in our country.
\end{abstract}

Keywords: Bachelor of Archaeology - Anthropology - Professional Building - Multivocality. 


\section{Referências bibliográficas}

BALÉE, W.

2009. The Four-Field Model of Anthropology in United States. Amazônica: Revista de Antropologia, (1):1, 28-53.

BEZERRA, M.

2008 Bicho de Nove Cabeças: Os Cursos de Graduação e a Formação de Arqueólogos no Brasil. Revista de Arqueologia, 21 (2): 139-154.

BINFORD, L.

1962 Archaeology as Anthropology. American Antiquity, 28 (2): 217-225.

BOAS, F.

1902 Some Problems in North America Archaeology. American Journal of Archaeology, 6 (1): 1-6.

CHILDE, G.

1944 The Future of Archaeology. Man, 44: 18-19.

1946 Archaeology and Anthropology. Southwestern Journal of Anthropology, 2 (3): 243-252.

DELACAMPAGNE, C.

2000 Une Histoire du Racisme. Paris: Le Livre de Poche, France Culture.

FERREIRA, L. M.

2008 Patrimônio, Pós-Colonialismo e Repatriação Arqueológica. Ponta de Lança: História, Memória e Cultura, 1: 37-62.

FOUCAULT, M.

1994 Entretien avec Michel Foucault. In: Dits et Écrits. Paris: Gallimard. Vol III: 140-160.

GOSDEN, C.

1999 Anthropology and Archaeology: A Changing Relationship. London: Routledge.

GUMERMAN, G; PHILLIPS, D. A. JR.

1978 Archaeology Beyond Anthropology. American Antiquity, 43 (2): 184-191.

HABU, J; FAWCETT, C; MATSUNAGA, J. M.

2008 Evaluating Multiple Narratives: Beyond Nationalist, Colonialist, Imperialist Arc aeologies. Berkley: Springer.

HINSLEY, C.

1981 The Smithsonian Institution and the American Indian: Making Anthropology in Victorian America. Washington: Smithsonian Institution Press.

HODDER, I.

1999 Archaeological Process: An Introduction. Oxford: Blackwell.

2008 Multivocality and Social Archaeology. In: Habu, J.; Fawcett, C.; Matsunaga, J.M. (Eds.) Evaluating Multiple Narratives:
Beyond Nationalist, Colonialist, Imperialist Archaeologies. Berkley, Springer: 196-200.

JOHNSON, M.

2000 La Nueva Arqueología. In: Teoría Arqueológica: una introducción. Barcelona, Ariel: 29-54.

LYMAN, R.L.

2007 Archaeology's Quest For a Seat at the High Table of Anthropology. Journal of Anthropological Archaeology, 26 (2): 133. 149.

MACGUIRRE, R.

1992 Archaeology and the First Americans. American Anthropologist, 93 (3): 816-836.

MARSHALL, Y.

2002 What is Community Archaeology? World Archaeology, 32 (2): 211-219.

MESKELL, L.

2002 Negative Heritage and Past Mastering in Archaeology. Anthropological Quarterly, 75 (3): 557-574.

PATTERSON, T.

1995 Toward a Social History of Archaeology in the United States. Ft. Worth, TX: Harcourt, Brace and Company.

PHILLIPS, $\mathrm{P}$.

1955 American Archaeology and General Anthropological Theory. Southwestern Journal of Anthropology, 11 (3): 246-250.

RENFREW, C.

1980 The Great Tradition versus The Great Divide: Archaeology as Anthropology? American Journal of Archaeology, 84 (3): 287-298.

SCHAAN, D.P.

2009 A Arqueologia Brasileira nos Trinta Anos da SAB. In: Schaan, D.; Bezerra, M.

(Orgs.) Construindo a Arqueologia no Brasil: a trajetória da Sociedade de Arqueologia Brasileira. Belém: SAB/GKNORONHA: 277-295.

SHACKEL, P.A.; CHAMBERS, E.J. (Eds.)

2004 Places in Mind: Public Archaeology as Applied Anthropology. London: Routledge.

SHANKS, M.; TILLEY, C.

1987 Social Theory and Archaeology. Cambridge: Polity Press.

SMITH, L.T.

1999 Decolonizing Methodologies: Research and Indigenous People. Dunedin: University of Otago Press. 
A Graduação em Arqueologia na UFPel: um currículo na interface entre Arqueologia e Antropologia.

Revista do Museu de Arqueologia e Etnologia, São Paulo, 19: 79-86, 2009.

SMITH, C.; WOBST, M.H. (Eds.)

2005 Indigenous Archaeologies: Decolonizing Theory and Practice. London: Routledge.

TRIGGER, B.G.

1984 Alternative Archaeologies: Nationalist, Colonialist, Imperialist. Man, 19: 355 370.

2008 Alternative Archaeologies in Historical Perspective. In: Habu, J.; Fawcett, C.; Matsunaga, J.M. (Eds.) Evaluating
Multiple Narratives: Beyond Nationalist, Colonialist, Imperialist Archaeologies. Berkley, Springer: 187-195.

TULLY, G.

2007 Community Archaeology: General Methods and Standards of Practice. Public Archaeology, 6: 155-187.

WILLEY, G; PHILLIPS, P.

1958 Method and Theory in Archaeology. Chicago: Chicago University Press.

Recebido para publicação em 30 de dezembro de 2009. 